\title{
Factors that Influence Patients in Choosing Their Treating Physicians in the Private Sector in Saudi Arabia
}

\author{
Abdulilah Al-Briek, Abdullah Al-Barrak, Kholood Al-Johi, Mohammed Al-Anazi, \\ Mohammed Al-Ateeq ${ }^{*}$, Nazish Masud \\ King Saud bin Abdulaziz University for Health Sciences, King Abdullah International Medical Research Center, \\ Ministry of National Guard, Health Affairs, Saudi Arabia \\ *Corresponding author: malateeq@hotmail.com
}

\begin{abstract}
Background: Choice of the treating physician by the patient is expected to increase the level of satisfaction and improve health care outcomes. The aim of this study was to explore the factors that may influence patients in choosing their treating physicians in the private health sector in Saudi Arabia. Methods: This was a cross-sectional study. An online questionnaire was distributed targeting Arabic-speaking adults, Saudis and non-Saudis, aged 18 years and above of both genders. The questionnaire included questions related to demographic data, personal factors of the physician, professional factors of the physician, health center/hospital factors, and methods patients use to access a preferred physician. Results: A total of 1582 participants completed the questionnaire. The most influential factor related to physician personal features was renown, reported by participants as either "very important" (31.7\%) or "somewhat important" (23.8\%), followed by physician appearance, considered to be "very important" and "somewhat important" by $28.6 \%$ and $21.1 \%$ of participants respectively. Regarding physician professional features, the most influential factor reported was previous experience of the physician for the patient or relative, considered "very important" by $66.5 \%$ of participants, followed by physician title (63.1\%) and sub-specialization (57.71\%). Regarding hospital factors, the availability of an appointment with a short waiting time was reported as "very important" by $59.2 \%$ of participants, followed by affordability of fees (50.0\%) and hospital access (46.84). Conclusion: Experience of the patient with the physician as well as physician title and sub-specialization significantly influence the choice of physician in the private sector in Saudi Arabia.
\end{abstract}

Keywords: physician characteristics, choice of treating physician, patient satisfaction, quality of care

Cite This Article: Abdulilah Al-Briek, Abdullah Al-Barrak, Kholood Al-Johi, Mohammed Al-Anazi, Mohammed Al-Ateeq, and Nazish Masud, "Factors that Influence Patients in Choosing Their Treating Physicians in the Private Sector in Saudi Arabia." American Journal of Public Health Research, vol. 6, no. 4 (2018): 173-181. doi: 10.12691/ajphr-6-4-1.

\section{Introduction}

Patient inducement to visit health care providers is a critical part of disease prevention and management, and ensuring patient well-being requires patient comfort with the treating physician. Hence, choice of the treating physician by the patient is expected to increase satisfaction, enhance compliance to the management plan, and improve health care outcome [1,2].

Patients' perspectives in choosing their treating physicians are variable, and studies in this area have revealed several important factors [3-8]

Since patients sometimes need to choose their doctor even before a health need arises, influencing factors are based not only on medical condition or active health issue. The influencing factors may be different from country to country because of variations in health delivery systems. In addition, public access to information related to physicians is not always available and this may limit choice and make decisions difficult.

In a study by Bornstein and colleagues from Louisiana State University, USA, several factors were found to affect the patient's choice of doctor, and the highest rated variables were: board certification of the doctor, physical appearance of the doctor's office, and physical appearance of the doctor [3].

In another study conducted in Minnesota, USA, 211 adults were asked to rate 12 demographic characteristics and another eight attributes of the family physicians they prefer. The results showed that $44 \%$ of female subjects preferred female physicians, and board certification was the most important physician attribute. [4] Mercado et al found, in a sample of 857 participants, that good patient care ranked first among the preferences followed by good communication skills [5].

Bernard et al found that a doctor's "approach to patient care" and "interpersonal skills/communication" were the most commonly cited factors by patients that affect their 
choice of physician, [6] while Razzouk et al found in a US study that "the degree of patient satisfaction with the quality of care received" and "the accessibility of the physician" were the two most relevant factors that impacted the choice of a physician [7].

In the Middle East, one study conducted in Iran including 493 participants demonstrated that the most commonly rated factor influencing physician choice was knowledge and experience of the physician, and a difference among age groups was significant [8].

According to the General Authority for Statistics, the population in Saudi Arabia is 31,742,308. [9] In 2016, the total number of physicians including Saudis and non-Saudis was 29,097, with 145 private hospitals and 2670 polyclinics [10].

In Saudi Arabia, it is almost always impossible for patients in the governmental health sector to choose their treating physician at the primary, secondary, and tertiary levels. By contrast, most of the time, patients in the private health sector need to choose their physician and decide which health center to visit, each time a health need arises, since they do not have an assigned physician.

To our knowledge, no previous studies in Saudi Arabia have investigated the factors that may affect patients in choosing their treating physicians in the private health sector. Therefore the aim of this study was to explore these factors in the private sector in Saudi Arabia, to identify the most common methods patients use to access their preferred physicians, and to examine possible associations between the studied factors and demographic characteristics.

\section{Methods}

This cross-sectional observational study was carried out in Saudi Arabia between August 1 and September 30, 2017. The study population was Arabic-speaking, Saudi and non-Saudi adults, aged 18 years and above, of both genders, living in Saudi Arabia, and visiting the private health sector regularly.

Findings from previous studies suggested that the influence of various factors ranged from $61.2 \%$ to $88.6 \%$. [3-8] We converted mean scores into percentages by dividing by 5 and multiplying by 100 . We assumed a minimum value of $61.2 \%$ from the literature as a benchmark with a precision level of $5 \%$. Our study required 383 subjects to estimate the recurrence rate with its corresponding 95\% confidence interval using the Clopper-Pearson formula. The sample size was set to increase the confidence in and precision of our results, and decrease uncertainty.

The questionnaire was developed based on our study objectives and after review of similar previous studies. The questionnaire was written in English and then translated into Arabic and reviewed for validation by an expert epidemiologist. A pilot study of 20 participants was conducted for clarity. Cronbach's alpha was reported for reliability testing. The questionnaire was divided into five sections. The first four sections included demographic data, personal factors of the physician, professional factors of the physician, and health center/hospital factors. A Likert scale was used from 1 to 5 , in which 1 represents not at all important and 5 represents very important; the total score was 25 for each section. For the outcome variables personal factors of the physician, professional factors of the physician, health center/hospital factors, and total score, the average was calculated and converted to a scale of $1-100$ by dividing the mean by 5 and multiplying by 100 . Section five contained questions related to methods patients use to access their preferred physician. A Likert scale was used from 1 (not used at all) to 5 (frequently used).

Participants were recruited using a non-probability convenience sampling method through different social media websites and applications.

Collected data were entered in Microsoft Excel. SPSS 22 was used for statistical analysis. Statistical significance was set to 0.05 or less. P-values were generated using Kruskal-Wallis and Mann-Whitney tests to compare median values across baseline characteristic of participants.

Approval of the study was obtained from King Abdullah International Medical Research Centre, Ministry of National Guard, Saudi Arabia. Consent was obtained from participants when questionnaires were distributed. All data were confidential and used only for research purposes.

\section{Results}

A total of 1582 participants completed the online questionnaire. Table 1 summarizes their demographic characteristics. The majority (95.9\%) of participants were Saudis, 54.9\% were aged 25-44 years (average age 33.94 years), $61 \%$ were men, and $57.7 \%$ lived outside Riyadh. The majority (63.1\%) were educated to university level, and $50.6 \%$ had a monthly income of 10.000 SR or less. Further, 45.5\% were government employees, 18.3\% were employed in the private sector, and $36.2 \%$ were unemployed or students. Most participants (65.2\%) had no insurance, $30.6 \%$ had insurance paid by the employer, and 4.2\% had self-funding health insurance.

As shown in Figure 1, among physician personal factors, renown and appearance were the most influential factors reported as either "very important" or "somewhat important" by $55.5 \%$ and $49.7 \%$, respectively, followed by physician nationality (37.6\%), gender (35.0\%), and age (32.0\%).

Figure 2 shows the impact of physician professional factors. Previous experience of the physician either for patients or someone known to them and physician position (GP, specialist, or consultant) were the most influential factors reported by $86.55 \%$ and $82.4 \%$ respectively. Other important factors were subspecialty $(78.1 \%)$, working in a government hospital (64.6\%), and academic title (29\%).

Factors related to hospital/health center reported by participants as either "very important" or "somewhat important" were availability of appointment (81.1\%), accessibility (71.2\%), fees for consultation and procedures (68.8\%), acceptance of medical insurance (63.6\%), and renown of the hospital/health center (58.8\%) (Figure 3).

The most frequently used method to find a preferred physician was asking a relative or friend, as reported by $62.5 \%$ of participants. Other reported ways were asking another physician (46.6\%), through the Internet or advertisements (35.4\%), and asking advice from health care providers other than physicians (33.7\%) or from appointment personnel or patient services (32.9\%) (Figure 4). 
Table 1. Baseline characteristics of respondents

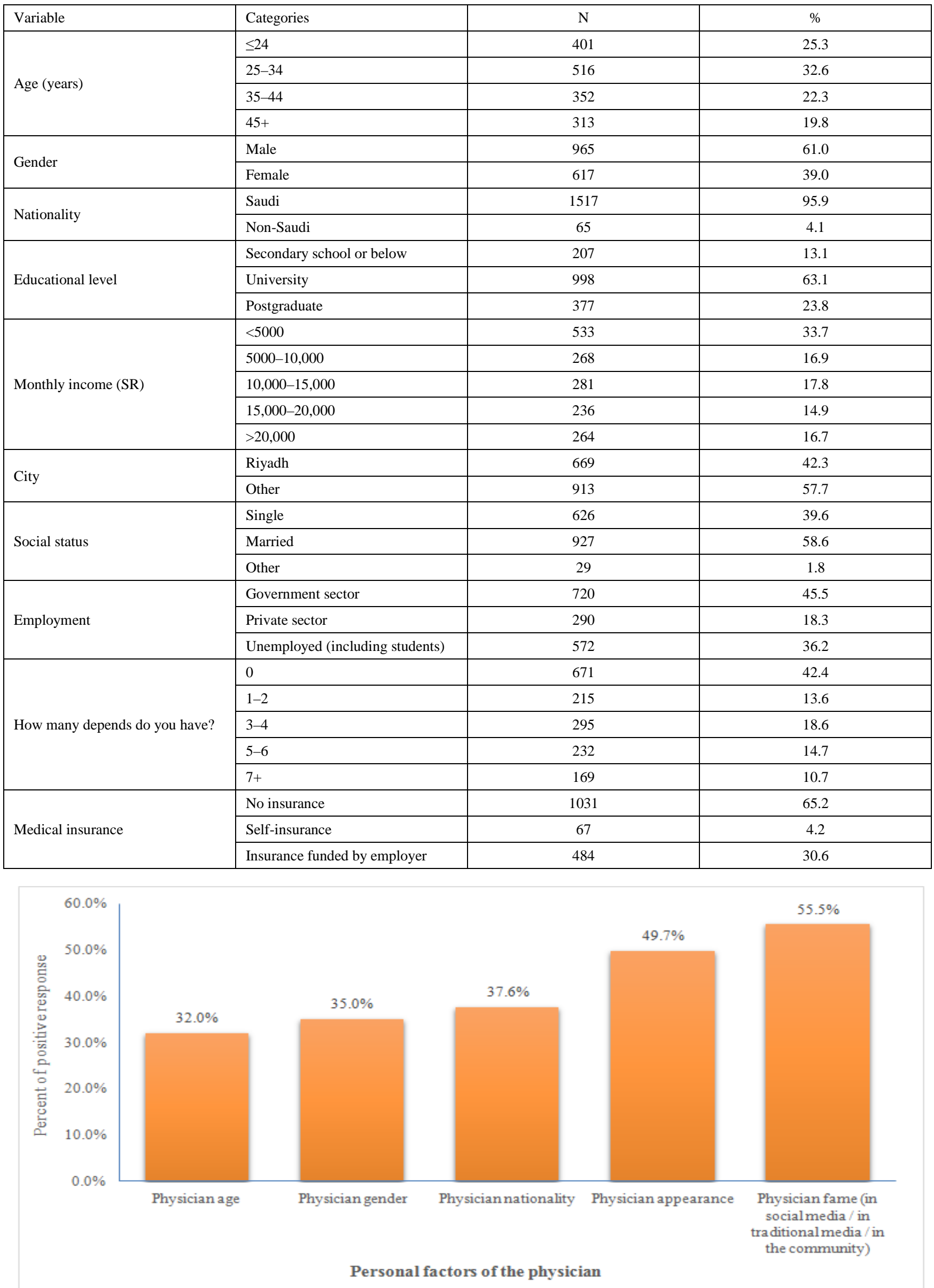

Figure 1. Personal factors of the physician (Positive response: "very important”/"somewhat important) 


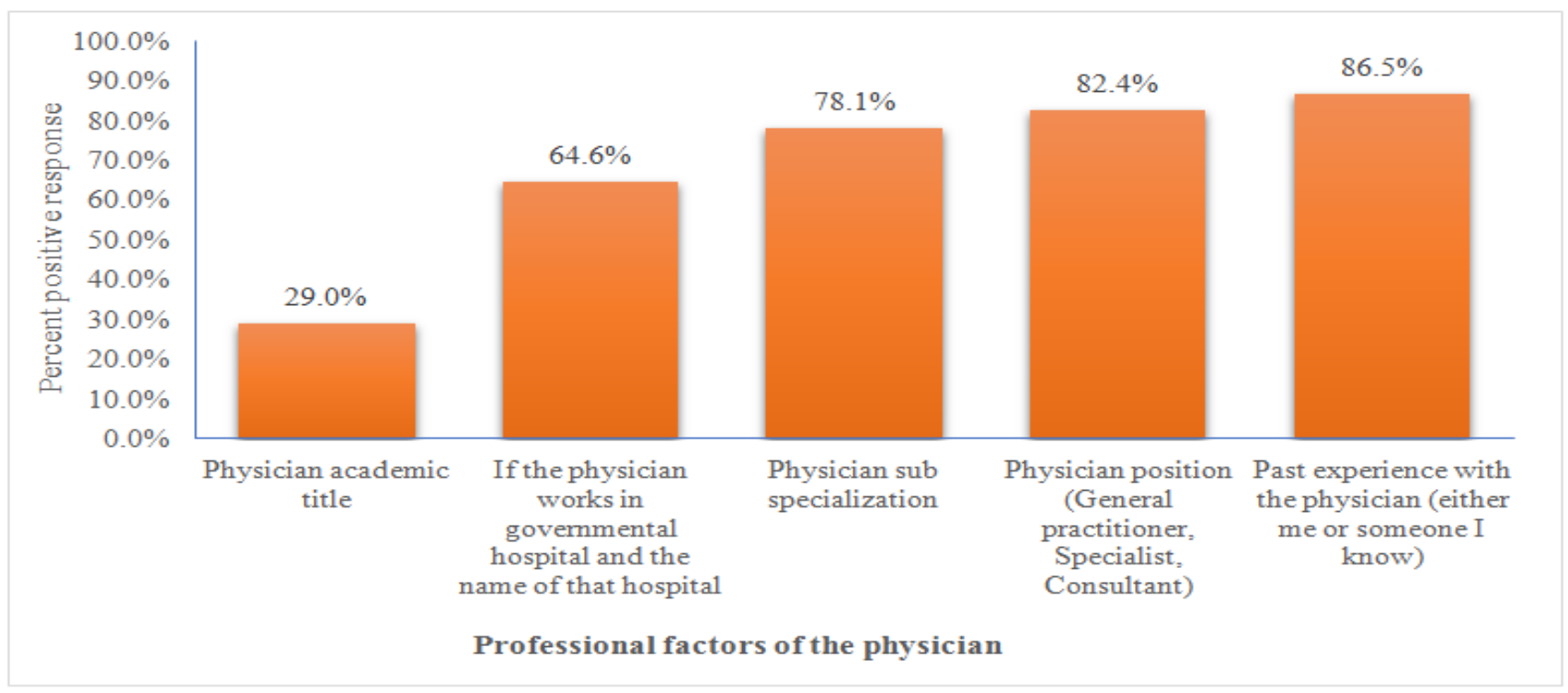

Figure 2. Professional factors of the physician

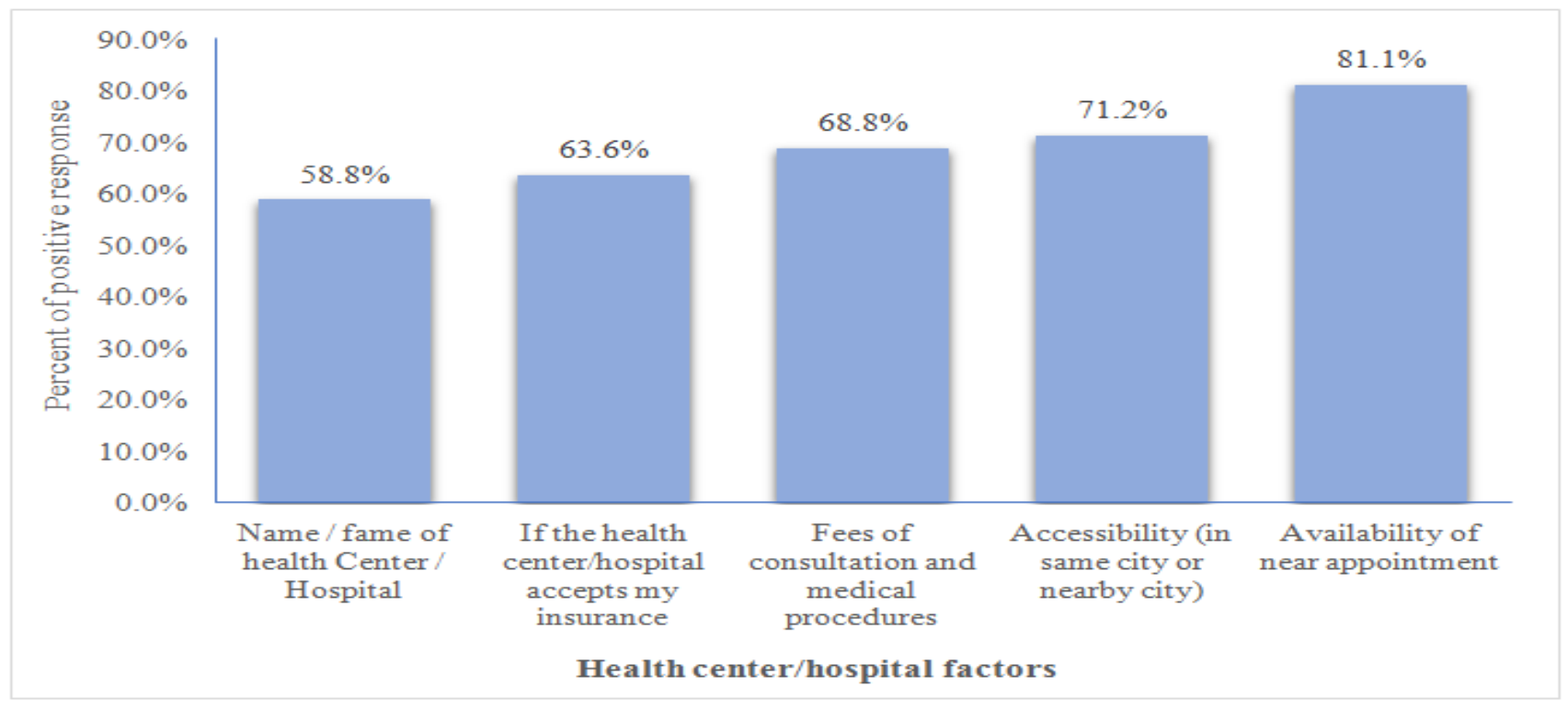

Figure 3. Health center/hospital factors

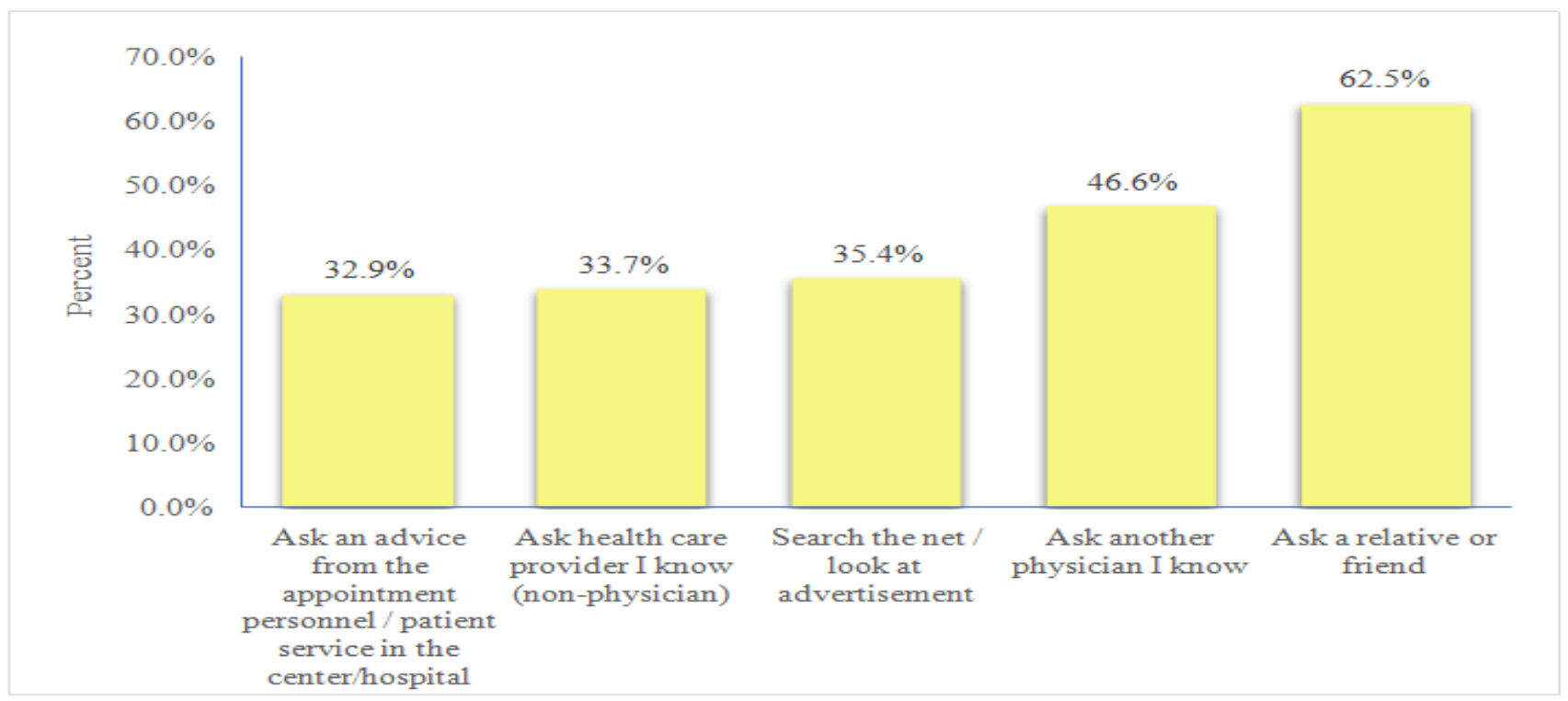

Figure 4. The method usually used to access your preferred doctor 
Table 2 summarizes the factors that influence patients in choosing their treating physician in the private health sector, showing the percentage of positive responses in relation to physician personal factors, physician professional factors, hospital/health centers factors, and the most frequently used ways to find a preferred physician.

Table 3 shows the most influential factors from the total score. Personal and professional factors of the physician have the highest impact on the total score influencing patients in choosing their treating physician $(\mathrm{R}=0.77$ and $\mathrm{R}=0.71$, respectively).

Table 4 shows the effect of respondents' baseline characteristics on the total score. Age, educational level, monthly income, social status, and employment (P-value $<0.001, \quad 0.013,<0.001,<0.001,<0.001$, and $<0.001$ respectively) all affected the total score.
Men were found to be more concerned about the age, nationality, appearance, position, academic title, and specialization of the physician. Women were more concerned about access to the hospital, fees, or acceptance of insurance by the hospital. Men were more likely to ask relatives and friends or another doctor about the preferred physician than women, whereas women were more likely to search the Internet or consider advertisements.

No difference was found between men and women with regard to physician gender, renown, employment by a governmental hospital or their experience of the doctor. Furthermore, there was no difference between men and women in influence of renown of the hospital or availability of appointments, or in seeking advice from health care workers or appointment/patient service personnel to find the preferred doctor.

Table 2. Factors influencing patients in choosing their treating physician in the private health sector

\begin{tabular}{|c|c|c|}
\hline & $\mathrm{N}$ & $\%$ of positive response* \\
\hline Personal factors of the physician & & 45.9 \\
\hline Physician age & 506 & 32.0 \\
\hline Physician gender & 554 & 35.0 \\
\hline Physician nationality & 594 & 37.6 \\
\hline Physician appearance & 787 & 49.7 \\
\hline Physician renown (social/traditional media, in the community) & 879 & 55.5 \\
\hline Professional factors of the physician & & 68.1 \\
\hline Physician academic title & 458 & 29.0 \\
\hline If working in governmental hospital, and name of hospital & 1022 & 64.6 \\
\hline Physician sub-specialization & 1235 & 78.1 \\
\hline Physician position (GP, specialist, consultant) & 1303 & 82.4 \\
\hline Past experience with the physician (either me or someone I know) & 1369 & 86.5 \\
\hline Health center/hospital factors & & 69.1 \\
\hline Name and renown of health center/hospital & 929 & 58.8 \\
\hline Whether health center/hospital accepts insurance & 639 & 63.6 \\
\hline Fees of consultation and medical procedures & 1088 & 68.8 \\
\hline Accessibility (in same or nearby city) & 1127 & 71.2 \\
\hline Availability of appointment with short waiting time & 1283 & 81.1 \\
\hline The way usually you use to access your preferred doctor & & 42.2 \\
\hline Ask advice from appointment/patient services personnel in the center/hospital & 520 & 32.9 \\
\hline Ask health care provider I know (non-physician) & 532 & 33.7 \\
\hline Search the Internet/advertisements & 561 & 35.4 \\
\hline Ask another physician I know & 738 & 46.6 \\
\hline Ask a relative or friend & 988 & 62.5 \\
\hline
\end{tabular}

* Positive response: “Very important” and “Somewhat important”/frequently used.

Table 3. The most influential factor on the total score

\begin{tabular}{|c|c|c|c|c|}
\hline Spearman's rho correlation coefficient & $\begin{array}{c}\text { Personal factors of the } \\
\text { physician }\end{array}$ & $\begin{array}{c}\text { Professional factors of the } \\
\text { physician }\end{array}$ & $\begin{array}{c}\text { Health center/hospital } \\
\text { factors }\end{array}$ & $\begin{array}{c}\text { Total } \\
\text { score }\end{array}$ \\
\hline Personal factors of the physician & 1.00 & 1.00 & & \\
\hline Professional factors of the physician & $0.36^{* *}$ & $0.12^{* *}$ & 1.00 & \\
\hline Health center/hospital factors & $0.17^{* *}$ & $\mathbf{0 . 7 1}^{* *}$ & $\mathbf{0 . 5 5}^{* *}$ & 1.00 \\
\hline Total score & $\mathbf{0 . 7 7}^{* *}$ & & & \\
\hline
\end{tabular}

** Correlation is significant at the 0.01 level (two-tailed). 
Table 4. The effect of respondents' baseline characteristics on the total score

\begin{tabular}{|c|c|c|c|c|c|}
\hline & & $\begin{array}{l}\text { Personal factors } \\
\text { of the physician }\end{array}$ & $\begin{array}{c}\text { Professional } \\
\text { factors of the } \\
\text { physician }\end{array}$ & $\begin{array}{c}\text { Health } \\
\text { center/hospital } \\
\text { factors } \\
\end{array}$ & Total score \\
\hline & & Median (Q1,Q3) & Median (Q1,Q3) & Median (Q1,Q3) & Median (Q1,Q3) \\
\hline \multirow{5}{*}{ Age (years) } & $\leq 24$ & $52(40,64)$ & $76(60,84)$ & $84(72,92)$ & $69(61,77)$ \\
\hline & $25-34$ & $60(52,72)$ & $80(68,92)$ & $84(72,92)$ & $73(67,80)$ \\
\hline & $35-44$ & $64(52,76)$ & $80(68,92)$ & $80(68,90)$ & $75(66,81)$ \\
\hline & $45^{+}$ & $68(52,80)$ & $84(72,92)$ & $80(65,90)$ & $75(67,83)$ \\
\hline & P-value ${ }^{1}$ & $<0.001$ & $<0.001$ & 0.012 & $<0.001$ \\
\hline \multirow{3}{*}{ Gender } & Male & $60(52,76)$ & $80(68,92)$ & $80(70,90)$ & $73(65,81)$ \\
\hline & Female & $60(44,72)$ & $80(64,88)$ & $80(70,92)$ & $72(63,80)$ \\
\hline & P-value & 0.935 & 0.202 & 0.616 & 0.935 \\
\hline \multirow{3}{*}{ Nationality } & Saudi & $60(48,72)$ & $80(68,92)$ & $80(70,90)$ & $73(64,80)$ \\
\hline & Non-Saudi & $60(44,72)$ & $72(60,84)$ & $80(76,88)$ & $71(61,81)$ \\
\hline & P-value ${ }^{1}$ & 0.719 & 0.004 & 0.802 & 0.188 \\
\hline \multirow{4}{*}{ Educational level } & Secondary school or below & $60(44,72)$ & $76(60,88)$ & $84(68,92)$ & $71(61,80)$ \\
\hline & University & $60(48,72)$ & $80(68,88)$ & $80(70,92)$ & $73(64,80)$ \\
\hline & Postgraduate & $64(52,76)$ & $84(72,92)$ & $80(70,90)$ & $74(67,81)$ \\
\hline & P-value $^{1}$ & 0.027 & $<0.001$ & 0.536 & 0.013 \\
\hline \multirow{6}{*}{ Monthly income (SR) } & $<5000$ & $56(44,68)$ & $76(64,84)$ & $84(72,92)$ & $71(63,79)$ \\
\hline & $5000-10,000$ & $60(48,72)$ & $76(64,88)$ & $84(72,92)$ & $73(64,80)$ \\
\hline & $10,000-15,000$ & $60(52,72)$ & $84(68,92)$ & $80(68,90)$ & $73(63,81)$ \\
\hline & $15,000-20,000$ & $64(52,76)$ & $84(72,92)$ & $80(68,90)$ & $74(65,81)$ \\
\hline & $>20,000$ & $68(52,78)$ & $84(76,92)$ & $80(68,88)$ & $75(69,81)$ \\
\hline & P-value ${ }^{1}$ & $<0.001$ & $<0.001$ & $<0.001$ & $<0.001$ \\
\hline \multirow{3}{*}{ City } & Riyadh & $60(48,72)$ & $80(68,88)$ & $80(70,90)$ & $73(64,80)$ \\
\hline & Other & $60(48,72)$ & $80(68,92)$ & $80(70,92)$ & $73(64,80)$ \\
\hline & P-value ${ }^{1}$ & 0.152 & 0.682 & 0.414 & 0.745 \\
\hline \multirow{4}{*}{ Social status } & Single & $56(44,68)$ & $76(64,88)$ & $80(70,92)$ & $71(63,79)$ \\
\hline & Married & $64(52,76)$ & $84(68,92)$ & $80(70,90)$ & $75(67,81)$ \\
\hline & Other & $60(48,68)$ & $76(64,84)$ & $80(65,90)$ & $67(61,77)$ \\
\hline & P-value ${ }^{1}$ & $<0.001$ & $<0.001$ & 0.41 & $<0.001$ \\
\hline \multirow{4}{*}{ Employment } & Government sector & $64(52,76)$ & $84(72,92)$ & $80(68,90)$ & $74(67,81)$ \\
\hline & Private sector & $64(48,76)$ & $76(64,88)$ & $80(72,90)$ & $72(63,80)$ \\
\hline & Unemployed (including students) & $56(44,68)$ & $76(64,88)$ & $84(72,92)$ & $71(63,79)$ \\
\hline & P-value $^{1}$ & $<0.001$ & $<0.001$ & 0.031 & $<0.001$ \\
\hline \multirow{6}{*}{ How many depends do you have? } & 0 & $56(44,68)$ & $76(64,88)$ & $80(70,92)$ & $71(63,79)$ \\
\hline & $1-2$ & $60(52,72)$ & $84(72,92)$ & $84(72,90)$ & $74(67,81)$ \\
\hline & $3-4$ & $60(52,76)$ & $84(72,92)$ & $80(70,92)$ & $75(67,81)$ \\
\hline & $5-6$ & $64(52,76)$ & $84(68,92)$ & $80(70,90)$ & $75(66,81)$ \\
\hline & $7+$ & $68(52,80)$ & $84(72,92)$ & $76(65,90)$ & $76(68,83)$ \\
\hline & P-value ${ }^{1}$ & 0.011 & 0.926 & 0.144 & 0.857 \\
\hline \multirow{4}{*}{ Medical insurance } & No insurance & $60(48,72)$ & $80(68,92)$ & $80(68,90)$ & $73(64,81)$ \\
\hline & Self-insurance & $56(44,72)$ & $76(60,84)$ & $84(76,88)$ & $71(61,80)$ \\
\hline & Insurance funded by employer & $60(48,72)$ & $78(68,88)$ & $84(72,92)$ & $73(64,80)$ \\
\hline & P-value $^{1}$ & 0.457 & 0.001 & 0.209 & 0.312 \\
\hline
\end{tabular}

\footnotetext{
${ }^{1}$ P-values were generated using Kruskal-Wallis and Mann-Whitney tests.
} 


\section{Discussion}

To our knowledge, this is the first study conducted locally to explore the factors that may influence patients in choosing their treating physicians in the private health sector.

Most of the participants were 25-44 years old, and this young age is expected as the study data were collected via an online survey; this is the usual age of social media and online application users.

Regarding insurance, most of the participants had no medical insurance; the rest were either insured by an employer $(30.6 \%)$ or had self-funded insurance (4.2\%). This can be explained within the context of the health system in Saudi Arabia, where all Saudi individuals have access to free government health services. However, it is obligatory for employers to provide health insurance for their employees (Saudis and non-Saudis). The statistics from the Council of Cooperative Health Insurance (CCHI) in its 2015 annual report stated that only 3.11 million Saudis had medical insurance or $30 \%$ of eligible citizens in the country, while 7.85 million or $79 \%$ of expatriates had coverage. [11] The report did not differentiate between self- and employer-funded insurance. The health system in Saudi Arabia is now undergoing reform whereby the funding of health services for the entire population will be provided by the government through a medical insurance like system. [12]

Five personal features of the physician were listed as possible influencing factors: age, gender, nationality, appearance, and renown. The most highly rated factor as "very important" or "somewhat important" was physician renown, on social media, in the traditional media, or in the community. This seems logical since no database of doctors and their qualifications are accessible to the public in Saudi Arabia. Therefore, well-known doctors in the media or community will be in demand. Renown was not one of the studied factors in similar studies internationally, and this is most likely related to differences in setting and health services delivery. What make a physician well known is not necessarily related to professional performance, qualifications, or credentials. Reputation in their communities may be related more to community advocacy, participation in different media, volunteering, role in governmental and non-governmental organizations, and other factors not related directly to the medical profession. To our knowledge, the correlation between physician fame and credibility has not been investigated.

The next listed item related to physician personal factors was appearance, where $49.7 \%$ of participants rated it as either "very important" or "somewhat important". The word "appearance" means the way the physician looks in terms of dressing, attire, hair style, physicianidentifying factors, etc. Physician appearance is considered an important tool of non-verbal communication that may affect doctor-patient rapport, [13,14] although the issue is complex and multifactorial. [15] One study conducted locally to explore Saudi patients' opinions about physician attire found most of participants prefer physicians to wear formal clothes, but the level of trust was not found to be related to external appearance. [16] Another study of the effect of pediatricians' attire on mothers' opinions found that the level of trust was related to physician appearance. [17] Another interesting study among Saudis found that Western attire with a white coat is preferred by most patients, but the Saudi national dress followed by Western dress is the preferred attire when physicians are dealing with social, sexual, and psychological problems. [18] Internationally, and in contrast to our findings, two studies demonstrated that most patients claimed that attire had no influence on their choice of physician. [13,19] This is clearly an issue related to culture and community values, and accordingly there is a wide variation between different communities in this regard.

Gender of the physician was ranked fourth as an influencing factor by participants in this study (35.5\%), and there was no difference between male and female participants, although it was expected that physician gender would make a difference for female patients in a conservative community like Saudi Arabia. This means that for the majority of participants in this study, gender of physician was not considered a determining factor in their choice, although in our questionnaire we did not specify the medical condition for which a physician may be consulted, and this may have revealed different results. In the United Arab Emirates, a community with a similar cultural background, a female doctor was preferred by $96.8 \%$ of 218 women for their gynecological problem and by $94.5 \%$ for their gastric problem. [20] In comparison, in a study in Turkey to explore the opinion of female patients, the majority had no preference for the gender of their gynecologist, [21] whereas in Alexandria, Egypt, most men $(81.4 \%)$ preferred to be examined by a male physician, and $41 \%$ of women preferred to be examined by a female physician. [22] The differences between men and women in medical practice is an area of extensive research, including differences with regard to communication and consultation to physical examination, use of resources, quality of care, and management outcome. [23,24,25,26] By contrast, in the USA, 44\% of women preferred a female physician and $93 \%$ of women agreed that, in general, male and female family physicians are equally competent. [4]

The physician professional factors were rated positively more often than physician personal factors or hospital and health center factors. This is evident by the high percentages of subjects who considered the professional factors either "very important" or "somewhat important". Previous experience of the physician, either for patients or someone known to them, was ranked at the top of the list. This was shown in other similar studies, where good patient care and communication received the highest mean scores in a list of factors that patients may consider in the selection of a primary care physician. [5,6,8] Positive experience of the patient is linked to better outcome of health care, and considered increasingly as an important aspect of quality assessment of health care systems. [27] A meta-analysis of 55 studies indicated consistent positive associations between patient experience, patient safety, and clinical effectiveness for a wide range of disease areas, settings, outcome measures, and study designs. [28] Good experience of a patient with a physician depends on several factors related to consultation process and setting, doctor-patient communication, and disease management, and may include emotional support and understanding, kindness and empathy, acknowledgment and respect of 
patients' values, exploring patients' ideas and concerns and meeting expectations, sharing the decision and management plan, medical expertise in management of different patient complaints, and the setting of the clinic and available resources.

The second item of physician professional factors rated positively by participants was physician position (GP, consultant, or specialist). Similarly, board certification was scored 4.43 out of 5 in the study by Mercado et al. [5] This is expected, since medical expertise and skills are likely to be greater for more qualified physicians in higher positions. In addition, being a consultant means being more specialized and this is another factor that was rated positively in our study by $78.1 \%$ of participants. The association between physician experience/age and quality of care and management outcome is inconsistent. While some studies found that better outcome and high quality of care were associated with physician board certification and specilaization, [29,30] a systematic review evaluating the relationship between clinical experience and performance suggested that physicians who have been practising for longer and older physicians possess less factual knowledge, are less likely to adhere to appropriate standards of care, and may also have poorer patient outcomes, and these effects seemed to persist in studies that adjusted for specialization. [31] By contrast, in a systematic review of 25 studies on the effect of surgeon training, specialization, and experience on outcomes for cancer surgery, it was found that specialized surgeons had better outcomes than non-specialized surgeons, and two of these studies demonstrated that increased time was associated with better outcomes. [32] The difference between these two and the remaining studies may be related to a difference in the specialty of the investigated physicians.

The majority of our subjects in this study did not recognize academic title as an important factor for physician selection, despite the fact that physicians working in universities are the main doctors working parttime in the private sector in Saudi Arabia. In a literature search, we could not identify any study that investigated the difference in patient care between university-affiliated physicians and others.

Interestingly, participants in our study were found to be concerned about whether or not the physician works in a government hospital, and the majority recognized it as "very important" or "somewhat important". This can be explained by the hypothesis that patients believe that physicians' credibility will increase if they work in a government health facility, especially tertiary hospitals in large cities, in addition to the private sector.

Bornstein et al in a similar study investigated 23 variables that may affect patients' choice of primary care physician, and found that the most important factor reported was whether or not the doctor was board certified. In general, variables relating to the doctor's professional expertise (e.g. board certification, specialization) were rated highly, whereas factors relating to the doctor's individual characteristics (e.g. gender, religion, marital status) were considered relatively unimportant. [3] This is consistent with our finding that physician professional factors were clearly more important to our participants than physician personal factors or hospital and health center factors in choosing the treating doctor. By contrast,
Engstrom et al found that, apart from board certification, personal attributes were rated highly. [4]

Regarding factors related to private hospital or health center, availability of an appointment with a short waiting time was ranked first, followed by accessibility of the hospital (in the same city or nearby). Almost all clinics in the private health sector in Saudi Arabia receive patients through self-referral, and bookings are made either by phone or onsite visit. In this context, having a short waiting time would be a significant determinant for booking with one doctor rather than another.

Most of the participants in our study frequently ask relatives or friends for information about their preferred physician, followed by asking another physician known to the participant. Less frequently used methods are searching the Internet, asking advice from other health care providers and finally asking the advice of appointment or patient services personnel. As mentioned above, no databases of physicians with their credentials or specialties are available to the public in Saudi Arabia. Therefore, alternative sources of information about physicians are still primitive and based on circulated and non-documented information within the community. In addition, information from relatives or friends may be accompanied by non-professional recommendations and advice, despite the difference in clinical needs of each patient. Recently, a smart phone application and social media accounts are emerging with paid services for physicians listing their specialties and credentials and the possibility of online booking. This service may provide a good alternative, but patients need to be cautious about the validity and reliability of information.

With regard to the differences in influencing factors between male and female participants, men were found to be more concerned about age, nationality, appearance, position, academic title, and specialization of the physician than women. This suggests that men may be more methodical in looking at the professional characters of the physician compared to women. On the other hand, female participants were found to be more concerned about access to hospital, hospital fees or acceptance of insurance by the hospital. It is not unexpected that women may be concerned about access in Saudi Arabia with poor public transport and where using private vehicles is not always easy.

\section{Conclusion}

The results of our study indicate that patients are rational in selecting the variables they deem essential to their choice of a treating physician. Participants were most concerned about variables relating to a doctor's personal characteristics, followed by pragmatic variables regarding physician professional factors, and then health center/hospital factors. Most participants were concerned about physician renown within the personal physician factors, while in terms of professional considerations their interest was mostly in past physician experience, and a short wait for an appointment as the most relevant health center factor. Asking advice from a relative or friend was the most frequently used method to access the preferred physician by the majority of our participants. 


\section{References}

[1] Schmittdiel, Julie, et al. "Choice of a personal physician and patient satisfaction in a health maintenance organization." Jama 278.19 (1997): 1596-99.

[2] Edward Krupat, PhD; John Hsu, MD, MBA, MSCE; Julie Irish, PhD; Julie A. Schmittdiel, MA; and Joe Selby, MD, MPH et al. "Matching patients and practitioners based on beliefs about care: results of a randomized controlled trial." The American journal of managed care 10.11 Pt 1 (2004): 814-22.

[3] Bornstein, Brian H., David Marcus, and William Cassidy. "Choosing a doctor: an exploratory study of factors influencing patients' choice of a primary care doctor." Journal of evaluation in clinical practice. 6.3 (2000): 255-62

[4] Engstrom, Suzanne, and Diane J. Madlon-Kay. "Choosing a family physician. What do patients want to know?." Minnesota medicine. 81.12 (1998): 22-6.

[5] Mercado, Francis, et al. "Patient preferences in choosing a primary care physician." Journal of primary care \& community health. 3.2 (2012): 125-31.

[6] Bernard, Matthew E., Jesse C. Sadikman, and Caren L. Sadikman. "Factors influencing patients' choice of primary medical doctors." Minnesota medicine. 89.1 (2006): 46-50.

[7] Razzouk, Nabil, Victoria Seitz, and Janet Marie Webb. "What's important in choosing a primary care physician: an analysis of consumer response." International Journal of Health Care Quality Assurance. 17.4 (2004): 205-11

[8] Yassini, S. M., M. A. Harrazi, and J. Askari. "The study of most important factors influencing physician choice." Procedia-Social and Behavioral Sciences 5. (2010): 1945-49.

[9] Statistical Sector [Internet]. General Authority for Statistics. 2017 [cited 20 July 2017]. Available from: www.stats.gov.sa.

[10] Team, M. (2017). Kingdom of Saudi Arabia - Ministry of Health Portal. [online] Moh.gov.sa. Available at: http://www.moh.gov.sa/en/Ministry/Statistics/book/Pages/default. aspx [Accessed 22 Jul. 2017].

[11] Council of Cooperative Health Insurance, Annual report 2015, at: http://www.cchi.gov.sa/en/Studies/AnnualReport/Pages/default. aspx.

[12] Jannadi B, Alshammari H, Khan A, Hussain R. Current structure and future challenges for the healthcare system in Saudi Arabia. Asia Pacific Journal of Health Management. 2008; 3(1): 43.

[13] Gjerdingen DK, Simpson DE, Titus SL. Patients' and physicians' attitudes regarding the physician's professional appearance. Archives of Internal Medicine. 1987 Jul 1; 147(7): 1209-12.

[14] Lill MM, Wilkinson TJ. Judging a book by its cover: descriptive survey of patients' preferences for doctors' appearance and mode of address. Bmj. 2005 Dec 22; 331(7531): 1524-7.

[15] Petrilli CM, Mack M, Petrilli JJ, Hickner A, Saint S, Chopra V. Understanding the role of physician attire on patient perceptions: a systematic review of the literature - targeting attire to improve likelihood of rapport (TAILOR) investigators. BMJ open. 2015 Jan 1; 5(1): e006578.
[16] Al-Ghobain MO, Al-Drees TM, Alarifi MS, Al-Marzoug HM, AlHumaid WA, Asiry AM. Patients' preferences for physicians' attire in Saudi Arabia. Saudi medical journal. 2012; 33(7): 763-7.

[17] Aldrees T, Alsuhaibani R, Alqaryan S, Alzahrani H, Alharethy S, Alghunaim A, Alohali S, Bawazeer M. Physicians' attire: Parents preferences in a tertiary hospital. Saudi Medical Journal. 2017 Apr 38(4): 435.

[18] Batais MA. Patients' attitudes toward the attire of male physicians: a single-center study in Saudi Arabia. Ann Saudi Med. 2014 Sep 1; 34(5): 383-9.

[19] Menahem S, Shvartzman P. Is our appearance important to our patients?. Family Practice. 1998 Oct 1; 15(5): 391-7.

[20] McLean M, Al Yahyaei F, Al Mansoori M, Al Ameri M, Al Ahbabi S, Bernsen R. Muslim women's physician preference: beyond obstetrics and gynecology. Health care for women international. 2012 Sep 1; 33(9): 849-76.

[21] Bal MD, Yılmaz SD, Beji NK, Uludağ S. Muslim women choice for gender of obstetricians and gynecologist in Turkey. Journal of Human Sciences. 2014 Jul 4; 11(2): 64-73.

[22] Zaghloul AA, Youssef AA, El-Einein NY. Patient preference for providers' gender at a primary health care setting in Alexandria, Egypt. Saudi medical journal. 2005; 26(1): 90-5.

[23] Lagro-Janssen AL. Medicine is not gender-neutral: influence of physician sex on medical care. Nederlands tijdschrift voor geneeskunde. 2008 May; 152(20): 1141-5.

[24] Schmittdiel J, Grumbach K, Selby JV, Quesenberry CP. Effect of physician and patient gender concordance on patient satisfaction and preventive care practices. Journal of general internal medicine. 2000 Nov 1; 15(11): 761-9.

[25] Henderson JT, Weisman CS. Physician gender effects on preventive screening and counseling: an analysis of male and female patients' health care experiences. Medical care. 2001 Dec 1 39(12): 1281-92.

[26] Kim C, McEwen LN, Gerzoff RB, Marrero DG, Mangione CM, Selby JV, Herman WH. Is physician gender associated with the quality of diabetes care?. Diabetes care. 2005 Jul 1; 28(7): 1594-8.

[27] Black N, Jenkinson C. Measuring patients' experiences and outcomes. BMJ: British Medical Journal (Online). 2009 Jul 2; 339

[28] Doyle C, Lennox L, Bell D. A systematic review of evidence on the links between patient experience and clinical safety and effectiveness. BMJ open. 2013 Jan 1; 3(1): e001570.

[29] Reid RO, Friedberg MW, Adams JL, McGlynn EA, Mehrotra A. Associations between physician characteristics and quality of care. Archives of Internal Medicine. 2010 Sep 13; 170(16): 1442-9.

[30] Norcini JJ, Kimball HR, Lipner RS. Certification and specialization: do they matter in the outcome of acute myocardial infarction? Academic Medicine. 2000 Dec 1; 75(12): 1193-8.

[31] Choudhry NK, Fletcher RH, Soumerai SB. Systematic review: the relationship between clinical experience and quality of health care. Annals of Internal medicine. 2005 Feb 15; 142(4): 260-73.

[32] Bilimoria KY, Phillips JD, Rock CE, Hayman A, Prystowsky JB, Bentrem DJ. Effect of surgeon training, specialization, and experience on outcomes for cancer surgery: a systematic review of the literature. Annals of surgical oncology. 2009 Jul 1; 16(7): 1799-808. 